\title{
Adaptation and cross-adaptation of the four gustatory qualities'
}

\author{
HERBERT L. MEISELMAN ${ }^{2}$ \\ UNIVERSITY OF MASSACHUSETTS
}

\begin{abstract}
On the basis of magnitude estimations of solutions of $\mathrm{NaCl}$, quinine sulfate, sucrose, and $\mathrm{HCl}$, a seven-step series of each compound was chosen. The concentration of each compound in the same ordinal position of the series was of approximately the same sensory magnitude. The middle concentration of each series was presented as an adapting stimulus, and the entire series was used to test the effects of $2 \mathrm{~min}$ of adaptation on magnitude estimations and quality reports. Both $\mathrm{NaCl}$ and sucrose adaptation markedly lowered magnitude estimations of test stimuli of the same compounds for concentrations lower than that of the adapting stimulus, but had little effect on higher concentrations. Cross-adaptation generally enhanced the magnitude estimations over those obtained in initial estimations. Neither adaptation nor cross-adaptation procedures produced quality changes.
\end{abstract}

Receptor mechanisms in gustation have been investigated with the technique of cross-adaptation, with which one seeks to determine whether or not prolonged stimulation with one compound, and the resulting sensory decrement, depresses responsiveness to other test compounds. If decreased responsiveness to another compound is observed, then it is assumed that the adapting stimulus and the test stimulus share common loci of stimulation on the gustatory receptors.

Currently, two opposing views suggest models for gustatory quality coding. The spectrum theory, or neural pattern theory, postulates that it is the pattern of firing rather than which fibers are firing that is important (Pfaffman, 1964; Erickson, 1967). In many cases, some of the same fibers respond to stimuli which are often considered to be perceptually quite different. The classic view of gustatory specificity postulates that separate receptors and fiber tracts mediate activities that covary with the four taste qualities (Bekesy, 1964, 1966). These two models of gustatory quality coding would predict different results from an attempt to demonstrate cross-adaptation between stimuli supposed to represent the four gustatory qualities. The specificity model would be supported by finding no cross-adaptation, i.e., receptors and nerves for each quality are separate and, hence, adaptation of any one should not affect the responsiveness of the others. On the other hand, the neural patterning view would predict some sensory decrement because of the common fibers involved. Prolonged stimulation with some compounds would be expected to adapt receptors and fibers that normally signal other compounds.

Cross-adaptation procedures with stimuli representing the four taste qualities have generally resulted in a reduction of thresholds from those determined without an adaptation procedure (Mayer, 1927; Dallenbach \& Dallenbach, 1943). However, threshold data and suprathreshold sensory magnitude data are apparently not equally affected by adaptation for salts (McBurney \& Lucas, 1966). Furthermore, equating sensory magnitude appears to be a necessary condition for obtaining cross-adaptation at least for salts, both in human psychophysical experiments (McBurney \& Lucas, 1966), and in electrophysiological recording of summated neural activity in the nucleus of the fasciculus solitarius of the rat (Halpern, 1967).

A series of experiments on $\mathrm{NaCl}$ adaptation have investigated changes in quality and sensory magnitude. McBurney (1966) obtained magnitude estimation functions of $\mathrm{NaCl}$ solutions following adaptation to $\mathrm{NaCl}$, and found a minimum magnitude estimation at the adaptation concentration, and an increase at both higher and lower concentrations of the $\mathrm{NaCl}$ test solutions. The lower concentrations were reported to have a sour-bitter quality, confirming the earlier report of Bartoshuk, McBurney, and Pfaffmann (1964). Bartoshuk (1968) obtained similar magnitude estimation functions and changes in quality reports for adaptation of $\mathrm{NaCl}$, quinine hydrochloride $(\mathrm{QHCl}), \mathrm{HCl}$, and sucrose. The low concentrations of $\mathrm{NaCl}$ were reported to taste bitter, $\mathrm{QHCl}$ sweet, $\mathrm{HCl}$ mixed, and sucrose bitter. The present experiment was designed to extend the findings with $\mathrm{NaCl}$ adaptation to suprathreshold concentrations, and to compare these findings with adaptation to other stimuli and crossadaptation among the stimuli.

\section{Subjects}

\section{METHOD}

Ss were four nonsmoking female students at the University of Massachusetts. Their ages ranged from 17 to 22 . These four were chosen from a larger group on the basis of their performance in a gustatory screening task previously described by Meiselman and Dzendolet (1967). None of the Ss had previous experience with gustatory adaptation or with magnitude estimation, although two of the Ss had participated in an experiment on quality changes with concentration (Dzendolet \& Meiselman, 1967). Ss were paid for their participation in the experiment.

\section{Stimuli}

All solutions were made with distilled water and reagent grade chemicals except for commerical grade sucrose. The adapting stimuli were the solutions of middle concentration in a seven-step series of each of the compounds $\mathrm{HCl}, \mathrm{NaCl}$, quinine sulfate $\left(\mathrm{QSO}_{4}\right)$, and sucrose. That is, the adapting concentration was the fourth member of a series of seven solutions placed at equal intervals along the dimension of $\log$ molar concentration.

In order to equate the solutions at each position in the series in terms of sensation magnitude, each solution was judged in relation to a standard solution of $0.36 \mathrm{M} \mathrm{NaCl}$ which was called Magnitude 10. Solutions of $\mathrm{NaCl}, \mathrm{QSO}_{4}$, sucrose, and $\mathrm{HCl}$ (Table 1) were presented on separate days for magnitude estimation using the $\mathrm{NaCl}$ standard. All stimulus concentrations lie above the recognition thresholds of salt, bitter, sweet, and sour, respectively, for these compounds (Pfaffmann, 1959). Solutions were maintained in a water bath at $35 \mathrm{deg} C$.

\section{Procedure}

To obtain initial magnitude estimation functions, each of the seven test solutions was presented on each of two days for

Table 1

Stimuli for Initial Magnitude Estimations

\begin{tabular}{cllcc}
\hline & \multicolumn{4}{c}{ Compound } \\
\cline { 2 - 5 } Concentration & $\mathrm{NaCl}$ & $\mathrm{QSO}_{4}$ & Sucrose & $\mathrm{HCl}$ \\
\hline 1 & $180 \mathrm{nM}$ & $0.032 \mathrm{nM}$ & $25 \mathrm{nM}$ & $2.00 \mathrm{nM}$ \\
2 & 225 & 0.052 & 50 & 2.85 \\
3 & 285 & 0.082 & 100 & 4.00 \\
4 & 360 & 0.130 & 200 & 5.70 \\
5 & 455 & 0.210 & 400 & 8.10 \\
6 & 570 & 0.330 & 800 & 11.50 \\
7 & 720 & 0.530 & 1600 & 16.50 \\
\hline
\end{tabular}


estimation using the $\mathrm{NaCl}$ standard. The order of the 21 presentations was randomized, with the restriction that the same solution was not presented more than three times consecutively. The standard was presented three times during each 50-min session, at the beginning, after the first seven solutions, and after the first 14 solutions. Testing followed this procedure: $\mathrm{S}$ was asked to pour into her mouth $10 \mathrm{ml}$ of solution from a beaker, hold the solution in her mouth for $3 \mathrm{sec}$, expectorate it into the sink in front of her, and then report the magnitude of that solution in relation to the standard. No rinses were used. Two minutes elapsed between successive presentations, and $3 \mathrm{~min}$ followed presentation of the standard. The order of testing the compounds was the same for all Ss: sucrose, $\mathrm{QSO}_{4}, \mathrm{HCl}, \mathrm{NaCl}$, sucrose, $\mathrm{QSO}_{4}, \mathrm{HCl}, \mathrm{NaCl}$.

The magnitude estimation functions which resulted from this procedure were used to construct four series of solutions in which the solutions at each ordinal position in each series were of the same sensation magnitude. The original concentrations of $\mathrm{NaCl}$ and $\mathrm{HCl}$ were maintained as above, but the concentrations of the sucrose and $\mathrm{QSO}_{4}$ series were changed so that the lowest position was called Magnitude 3, the middle 10, and the highest 20 . The new concentrations for the sucrose series were 88, 140,220,350, 560,880 , and $1400 \mathrm{mM}$. For $\mathrm{QSO}_{4}$ they were $0.037,0.059$, $0.094,0.155,0.237,0.375$, and $0.600 \mathrm{mM}$.

During the main body of the experiment each compound was used for the adapting solution and test compound series. $S$ was given a beaker containing $50 \mathrm{ml}$ of adapting solution and asked to pour into her mouth an amount which comfortably filled it. Generally, about $20 \mathrm{ml}$ was taken. She was instructed to move her tongue during the adaptation procedure to insure that the solution penetrated into all the tongue folds. After $1 \mathrm{~min}$, she expectorated and immediately took more of the adapting solution. Replacement of the adapting solution was used to avoid excessive salivary dilution of the stimulus. At the end of the second minute, $S$ expectorated the adapting solution and immediately poured $10 \mathrm{ml}$ of test solution into her mouth. After $5 \mathrm{sec}$, she expectorated the test solution, and then first gave a quality report, followed by the magnitude estimation. Forty-five seconds after expectorating the test solution, the next 2-min adaptation began. In this way, each test stimulus of a particular compound was tested twice during each of two sessions. Within each session, the order of the 14 test stimuli was randomized. All combinations of adaptation and test compound were completed before the entire series of sessions was replicated. The order of the combinations of adapting and test stimuli was approximately the same for all Ss.

\section{RESULTS}

The mean initial magnitude estimations are presented in Fig. 1 on log-log coordinates in order to estimate their closeness to power functions. Although the concentration values differ for each function, the four functions have been superimposed on the same abscissa in Fig. 1 for easier comparison. Calculation of the exponents of the best-fitting straight lines with the method of least squares (Edwards, 1962) yielded 1.43 for $\mathrm{NaCl}, 0.98$ for $\mathrm{QSO}_{4}, 0.70$ for sucrose, and 0.87 for $\mathrm{HCl}$.

Two occurrences prevented the gathering of all the data for the main part of the experiment. $\mathrm{HCl}$ adaptation was discontinued as an adapting condition because three Ss reported that repeated 2-min adaptations with $57 \mathrm{mM} \mathrm{HCl}$ resulted in a painful irritation of the mouth, especially the upper palate, which lasted for periods up to one week. Secondly, S D.M. completed two replications of each combination of adapting and test stimulus, instead of the four replications completed by the other three Ss.

In four instances Ss labeled a solution with a quality name usually associated with another of the compounds. These all occurred at the lowest concentration of the test compound, and in cases in which the adapting and test compounds were the same. A sweet report was elicited when $0.36 \mathrm{M} \mathrm{NaCl}$ was the adaptation stimulus and when $0.18 \mathrm{M} \mathrm{NaCl}$ was the test stimulus, and when $0.1550 \mathrm{mM} \mathrm{QSO}_{4}$ was the adaptation stimulus and $0.0375 \mathrm{mM}$ $\mathrm{QSO}_{4}$ the test stimulus. With $350 \mathrm{mM}$ sucrose as the adaptation stimulus and $88 \mathrm{mM}$ sucrose as the test stimulus there were reports

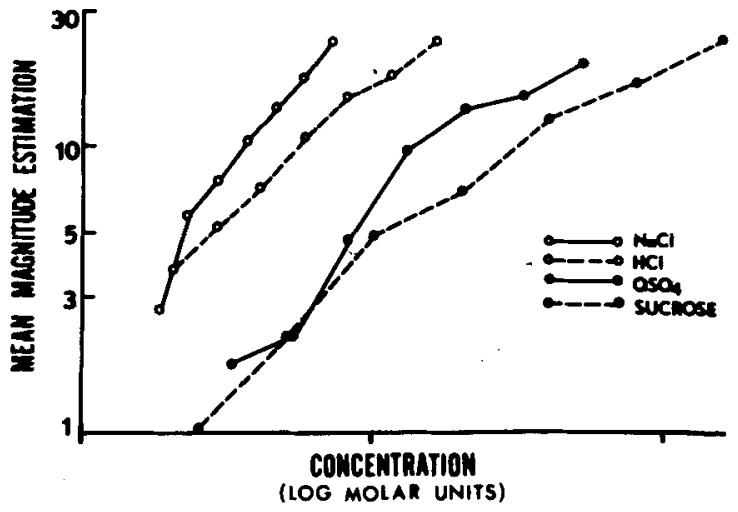

Fig. 1. Log mean initial magnitude estimation as a function of $\log$ concentration. Each point represents the mean of six presentations to each of four Ss. The four functions are superimposed on one abscissa for ease of comparison; the abscissa for each stimulus compound is different.

of bitter twice for one S. The magnitude estimations of the four quality changes were not included in the data submitted to statistical tests. Hence, all figures present both magnitude estimation data and quality data, since the quality is always that usually associated with the compound.

- Two analyses of variance were performed on the magnitude estimations resulting from the adaptation and cross-adaptation procedures. First, a five-factor repeated measurements analysis of variance excluded the data of S D.M. so that the effects of procedural variables could be investigated. Because of the small size of the effects of the procedural variables and because the mechanisms underlying them are unclear, they will not be treated in this paper. The interested reader is referred to a previous report (Meiselman, 1968a). Second, a three-factor analysis was run on the means of each combination of adapting and test stimulus for each $S$. With one exception, all sources of variance that were significant in the five-factor analysis of variance, and were present in the three-factor analysis, were found to be significant there also. No additional significant cources of variance were found in the three-factor analysis. In the five-factor analysis, the sensory magnitudes of sucrose and $\mathrm{HCl}$ increased more rapidly over the range of concentrations of test stimuli than did $\mathrm{NaCl}$ and $\mathrm{QSO}_{4}$. In other words, the plots of sensory magnitude as a function of concentration were of steeper slope for sucrose and $\mathrm{HCl}$ than they were for $\mathrm{QSO}_{4}$ and sucrose. The $\mathrm{K}$ by $\mathrm{C}$ interaction was not found to be significant in the three-factor analysis and will be ignored in the discussion of results.

A three-factor repeated measurements analysis of variance (Myers, 1966) assessed the effects of the following variables on the mean magnitude estimations given by each of the four Ss: test compound $(\mathrm{K})$, adapting compound $(\mathrm{A})$, and concentration of test compound (C). Ss tended to assign higher numbers to test solutions of $\mathrm{HCl}(16.51)$ than to test solutions of $\mathrm{NaCl}$ (13.17), $\mathrm{QSO}_{4}$ (12.42), or sucrose (12.05). The tendency for increasing

Table 2 Three-Factor Analysis of Variance

\begin{tabular}{|c|c|c|c|}
\hline Source & $\mathrm{df} / \mathrm{df}$ & F & $\mathrm{p}$ \\
\hline Test compound $(\mathrm{K})$ & $3 / 9$ & 4.780 & .05 \\
\hline $\mathrm{HCl}$ vs $\mathrm{QSO}_{4}, \mathrm{NaCl}$, sucrose & $1 / 9$ & 13.596 & .01 \\
\hline Test compound concentration (C) & $6 / 18$ & 36.036 & .001 \\
\hline$C_{3}$ vs $C_{4}$ & $1 / 18$ & 4.441 & .05 \\
\hline $\mathrm{C}_{4}$ vs $\mathrm{C}_{5}$ & $1 / 18$ & 5.703 & .05 \\
\hline $\mathrm{C}_{6}$ vs $\mathrm{C}_{7}$ & $1 / 18$ & 6.048 & .05 \\
\hline Adapting compound (A) & $2 / 6$ & 15.288 & .005 \\
\hline $\mathrm{NaCl}$ vs $\mathrm{QSO}_{4}$, sucrose & $1 / 6$ & 35.438 & .005 \\
\hline $\mathbf{K} \times \mathbf{A}$ & $6 / 18$ & 8.435 & .001 \\
\hline $\mathrm{K} \times \mathrm{C} \times \mathrm{A}$ & $36 / 108$ & 2.090 & .005 \\
\hline
\end{tabular}


magnitude estimations with increasing concentration of the test stimulus was demonstrated by the highly significant effect of $\mathbf{C}$. Arithmetic means of the levels of $\mathrm{C}$ were as follows, beginning with $C_{1}: 5.01,6.73,9.16,12.72,16.75,20.12,24.28$. Adaptation with $\mathrm{NaCl}$ produced significantly smaller mean magnitude estimations (10.76) than adaptation with either $\mathrm{QSO}_{4}(14.47)$ or sucrose (15.38).

The $K$ by $A$ interaction and the $K$ by $C$ by $A$ interaction were both significant. Adapting solutions of $\mathrm{NaCl}$ and sucrose depressed the sensory magnitudes of the test stimuli of the same compounds below the level of the adapting stimulus. $\mathrm{QSO}_{4}$ test stimuli were equally affected by both $\mathrm{NaCl}$ and $\mathrm{QSO}_{4}$ adaptation. Since $\mathrm{HCl}$ was never used as an adapting solution, its effects could not be assessed. The $K$ by $C$ by $A$ interaction is presented in Fig. 2 as four groups of functions, with each group representing the effects of adaptation and cross-adaptation on a particular compound. Since the seven-step series of concentrations for each compound is represented along the abscissa, the abscissae of the four groups of functions are different.

The exponents of the best-fitting straight lines of Fig. 2 were calculated with the method of least squares (Table 3). In all cases, exponents calculated for the concentrations below the adapting concentration $\left(C_{1}, C_{2}, C_{3}\right)$ were higher than those calculated for the higher concentrations $\left(C_{5}, C_{6}, C_{7}\right)$. There was a reduction in the size of the exponents from the initial magnitude estimations to those obtained with the cross-adaptation and adaptation procedures, except for the whole-function exponents representing $\mathrm{NaCl}$ adaptation and sucrose adaptation, both of which were markedly increased.

\section{DISCUSSION}

The adaptation and cross-adaptation procedures failed to produce any systematic changes in the quality of test stimuli. Bartoshuk et al (1964), McBurney (1966), and Bartoshuk (1968) all reported that test stimuli below the level of the adapting concentration were of a quality other than that usually associated with the compound, and that this subadapting quality increased in intensity as one moved to lower test stimulus concentrations.

Several points of difference between the studies deserve comment. The adaptation procedure used in the present study has been demonstrated by Meiselman (1968b) to produce only partial adaptation. The initial sensory magnitudes of $\mathrm{NaCl}$ and of sucrose dropped by about $60 \%$ during 2 -min adaptations and by about $40 \%$ for $\mathrm{QSO}_{4}$ in that study. McBurney (1966) noted that his dorsal tongue flow system did not produce complete adaptation, i.e., disappearance of the sensation, and Bartoshuk (1968) found that some Ss did not completely adapt to $\mathrm{HCl}$ and $\mathrm{QHCl}$ in the $40 \mathrm{sec}$ allotted, but that complete adaptation was not a necessary condition for elicitation of subadapting qualities. It is doubtful, therefore, that the different results of the prior studies and those of the present experiment are due primarily to different degrees of adaptation.

The earlier studies did not report any attempt to screen their Ss for gustatory quality responsiveness. Meiselman and Dzendolet (1967) found that many college students performed poorly in a quality-naming task even when given the correct answers through a correction procedure. Bartoshuk (1968) has suggested that some of her Ss were confusing sour and bitter, a phenomenon mentioned by Meiselman and Dzendolet (1967) as being especially

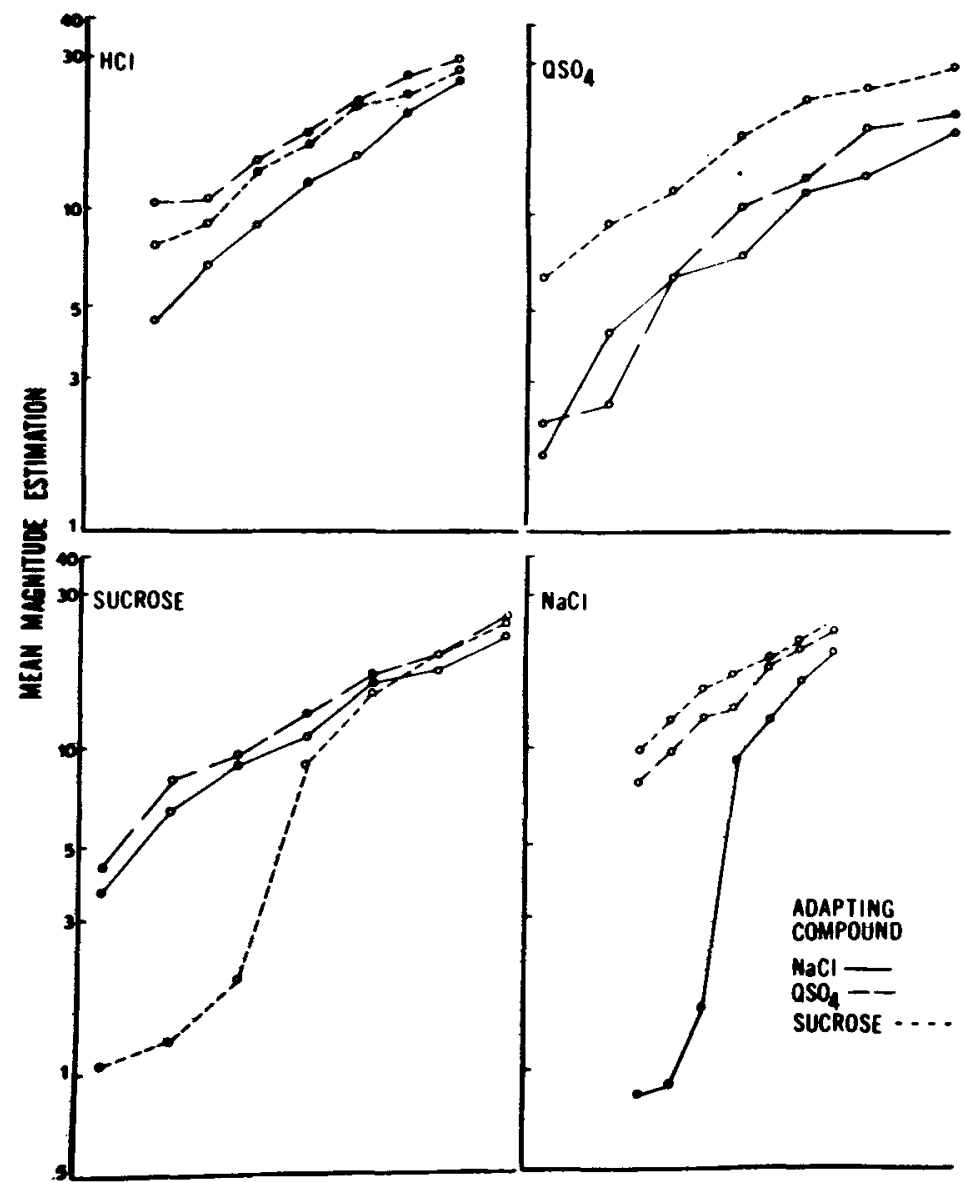

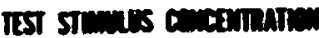

I LOG MOLAR UNIT
Fin. 2. Los mean mumitude estimation as a function of bs concentration of test stimuli after adaptution with $\mathrm{NaC1}, \mathrm{QSO}_{4}$, or sucrose. Note that the abocien for each compound, i.e., for each grouping of these functions, is different. 
Table 3

Exponents of the Bext-Fitting Strintht Lines of the $K \times \mathbf{C} \times \mathbf{A}$ Interaction

\begin{tabular}{|c|c|c|c|c|c|}
\hline \multirow{2}{*}{$\begin{array}{c}\text { Test } \\
\text { Compound }\end{array}$} & \multirow{2}{*}{$\begin{array}{c}\text { Concentration } \\
\text { Range }\end{array}$} & \multicolumn{3}{|c|}{ Adapting Compound } & \multirow{2}{*}{$\begin{array}{c}\text { Initial } \\
\text { Estimations }\end{array}$} \\
\hline & & $\mathrm{NaCl}$ & $\mathrm{QSO}^{4}$ & Sucrose & \\
\hline \multirow[t]{3}{*}{$\mathrm{NaCl}$} & low & 1.35 & 0.97 & 1.07 & 2.26 \\
\hline & high & 1.10 & 0.57 & 0.68 & 1.22 \\
\hline & total & 2.87 & 0.84 & 0.67 & 1.43 \\
\hline \multirow[t]{3}{*}{$\mathrm{QSO}_{i}$} & low & 1.53 & 1.16 & 0.68 & 1.91 \\
\hline & high & 0.48 & 0.50 & 0.25 & 0.43 \\
\hline & total & 0.80 & 0.89 & 0.56 & 0.98 \\
\hline \multirow[t]{3}{*}{ Suctose } & low & 0.97 & 0.86 & 0.66 & 1.10 \\
\hline & high & 0.36 & 0.44 & 0.55 & 0.48 \\
\hline & total & 0.62 & 0.59 & 1.31 & 0.70 \\
\hline \multirow[t]{3}{*}{$\mathrm{HCl}$} & low & 1.00 & 0.46 & 0.78 & 0.97 \\
\hline & high & 0.67 & 0.38 & 0.33 & 0.65 \\
\hline & total & 0.77 & 0.52 & 0.60 & 0.87 \\
\hline
\end{tabular}

Note: Separate exponents were calculated for each function of the $K \times C \times A$ interaction (Fig. 2) at low concentration $\left(C_{1}, C_{2}, C_{3}\right)$, at high concentration $\left(C_{5}, C_{6}, C_{7}\right)$, and for all concentrations $\left(C_{1}, \ldots, C_{7}\right)$. The analogous exponents for the initial magnitude estimation functions (Fig. 1) are presented for comparison.

common. A screening test would probably have eliminated those Ss. The sour-bitter confusion might also be responsible for the tendency of Ss in earlier studies to report the quality of subadapted $\mathrm{NaCl}$ as sour-bitter rather than sour or bitter.

Last, and perhaps most important, in comparing the present results with the prior studies is the range of concentrations involved. The highest concentration of $\mathrm{NaCl}$ which showed a sour and/or bitter taste after adaptation was $0.03 \mathrm{M}$ in the earlier studies. This is considered to be the recognition threshold for saltiness in $\mathrm{NaCl}$, and the concentration at which solutions of $\mathrm{NaCl}$ change in quality from salty to sweet as one decreases concentration (Pfaffmann, 1959). It is assumed that salty and sweet responses to $\mathrm{NaCl}$ would show frequency distributions of the form described by Dzendolet and Meiselman (1967) for other simple salts. Thus, the presence of a quality change at about $0.03 \mathrm{M} \mathrm{NaCl}$ is not necessarily related to the adaptation procedure. The interesting point is that the quality change reported for $\mathrm{NaCl}$ by Bartoshuk et al and by McBurney was from salty to sour-bitter. Perhaps the sour-bitterness reported in earlier studies is dependent on the quality change from salty to sweet already existing in responses to $\mathrm{NaCl}$ solutions. This suggestion is supported by Bartoshuk's findings of predominantly bitter subadapting tastes for both $\mathrm{NaCl}$ and sucrose. Similar mechanisms might account for other subadapting tastes.

The assignment of higher average magnitude estimations to $\mathrm{HCl}$ was due to the fact that $\mathrm{HCl}$ adaptation was not used, thus elevating the average estimation given to $\mathrm{HCl}$ test stimuli. Sucrose adaptation appears to have affected only sucrose test stimuli, while $\mathrm{NaCl}$ adaptation produced lower estimations than adaptation with either sucrose or $\mathrm{QSO}_{4}$ for test stimuli of $\mathrm{QSO}_{4}$, $\mathrm{HCl}$, and $\mathrm{NaCl}$ itself. It is unclear whether this finding is related to the fact that $\mathrm{NaCl}$ was used as the standard, or whether $\mathrm{NaCl}$ adaptation masked the other solutions. Clearly, however, the comparison should be made between $\mathrm{NaCl}$ and sucrose adaptation, both of which had strong effects.

Adapting solutions of $\mathrm{NaCl}$ and sucrose depressed the sensory magnitudes of test stimuli of the same compounds below the level of the adapting stimulus. Magnitude estimations of the lower concentrations of $\mathrm{QSO}_{4}$ were not reduced in sensory magnitude by the $\mathrm{QSO}_{4}$ adaptation procedure, although it should be noted that the $\mathrm{QSO}_{4}$ test series used in the adaptation procedure was not the same one used in the initial testing. The exponent of the power function fitted to the initial estimations is 0.98 , whereas the exponent fitted to the $\mathrm{QSO}_{4}$-adapted test stimuli is 0.89 .

Magnitude estimations of $\mathrm{QSO}_{4}$ adaptation obtained from the same Ss and reported earlier by Meiselman (1968b) indicated that with 45 -sec intervals between adaptations, less adaptation was shown to QSO, than to either $\mathrm{NaCl}$ or sucrose. Apparently, $\mathrm{QSO}_{4}$ adaptation did not take place to the degree that it exerted a noticeable affect on the test stimulus. Both Mayer (1927), and Dallenbach and Dallenbach (1937) found changes in thresholds of other compounds after QHCl adaptation. However, the recent demonstration of cross-adaptation of salts by McBurney and Lucas (1966) led them to conclude that thresholds and magnitude estimations were not equally affected by adaptation. It is suggested that the present experiment be repeated with other bitter compounds and with another method of stimulus presentation to attempt to produce more complete bitter adaptation.

Thus, the cross-adaptation procedure did not produce decreases in the sensory magnitude of the test stimuli. This is interpreted as providing support for the classic view of gustatory quality coding through specific, separate receptors. However, such a conclusion is sharply limited by the lack of evidence for $\mathrm{HCl}$ adaptation and $\mathrm{QSO}_{4}$ adaptation in the present experiment. It is suggested that cross-adaptation experimentation be attempted with other stimuli for sour and bitter.

The exponents of straight lines fitted to each end of the adaptation functions were reasonably close to the exponents obtained from the initial magnitude estimations of the entire functions, and to exponents of cases of attempted crossadaptation. Exponents fitted to the entire adaptation function for $\mathrm{NaCl}$ and sucrose were markedly increased. For example, the exponent of the initial magnitude estimation function of sucrose was $\mathbf{0 . 7 0}$. The exponents of the high and low concentrations of the adaptation functions were 0.66 and 0.55 , respectively, while the exponent for the overall adaptation function was 1.31. Adaptation with $\mathrm{NaCl}(0.62)$, or with $\mathrm{QSO}_{4}(0.59)$ produced little change in the overall exponent for the sucrose function. Thus, each end of the adaptation function approximates the form of the entire psychophysical function for a compound. The adaptation procedure apparently shifts the function of the lower concentrations $\left(C_{1}, C_{2}, C_{3}\right)$ down the scale of sensory magnitude without changing the form of the function. Thus, the effect of adaptation was apparently greatest near the adapting concentration as suggested by McBurney (1966).

The cross-adaptation procedure appears to have produced a rather marked enhancement effect. This is observed in Figs. 1 and 2. The test stimuli were chosen so that each solution of lowest concentration would have a magnitude estimation of approximately 3 , each adapting concentration approximately 10 , and each highest concentration approximately 20 . It is clear in Fig. 2 that, with the exception of the adaptation functions, the functions generally begin at a level much higher than an estimation of 3 , are higher than 10 at the middle concentration, and rise to as much as 30. Furthermore, the exponents of the best-fitting straight lines of these functions show that generally the exponents are slightly smaller than those found for the same compounds in the initial magnitude estimations. In other words, the sensory magnitude has not only been elevated by the cross-adaptation procedure, but the increase in sensory magnitude with concentration has been altered. The general enhancement in sensory magnitude observed in the present study is in agreement with the decreased thresholds observed by Mayer (1927) for most cases of cross-adaptation among stimuli representing the four taste qualities. Either of two different mechanisms could account for this enhancement effect: (1) Possibly the cross-adaptation procedure actually affects receptors other than those specifically activated by the adapting compound, but rather than decreasing their responsiveness, the effect is one of increased sensitivity. (2) The enhancement could result from an attentional variable. The estimated strength of a solution might have been raised; by its contrast to a different adapting compound. When viewed by itself, as in the initial estimations, it did not seem as intense as when contrasted with a different compound

\section{REFERENCES}

BARTOSHUK, L. M. Water taste in man. Perception \& Psychophysics, 1968, 3, 69-72. 
BARTOSHUK, L. M., McBURNEY, D. H., \& PFAFFMANN, C. Taste of sodium chloride solutions after adaptation to sodium chloride: Implications for the "water taste." Science, 1964, 143, 967-968.

BEKESY, G. von. Sweetness produced electrically on the tongue and its relation to taste theories. Journal of Applied Physiology, 1964, 19; $1105-1113$.

BEKESY, G. von. Taste theories and the chemical stimulation of single papillae. Journal of Applied Physiology, 1966, 21, 1-9.

DALLENBACH, J. W., \& DALLENBACH, K. M. The effects of bitter adaptation on sensitivity to the other taste qualities. American Journal of Psychology, 1943, 56, 21-31.

DZENDOLET, E., \& MEISELMAN, H. L. Gustatory quality changes as a function of solution concentration. Perception \& Psychophysics, 1967, 2, 29-33.

EDWARDS, A. L. Statistical methods of the behavioral sciences. New York: Holt, Rinehart \& Winston, 1962.

ERICKSON, R. P. Neural coding of taste quality. In M. R. Kare and O. Maller (Eds.), The chemical senses and nutrition. Baltimore: The Johns Hopkins Press, 1967. Pp. 313-327.

HALPERN, B. P. Some relationships between electrophysiology and behavior in taste. In M. R. Kare and O. Maller (Eds.), The chemical senses and nutrition Baltimore: The Johns Hopkins Press, 1967. Pp. 21 3-241.

MAYER, B. Messende Untersuchungen über die Umstimmung des Geschmackswerkzeugs, Zeitschrift fur Physiologie und Psychologie des Sinnesorgane, 1927, 58, 133-152.

McBURNEY, D. H. Magnitude estimation of the taste of sodium chloride after adaptation to sodium chloride. Journal of Experimental Psychology, $1966,72,869-875$.

McBURNEY, D. H., \& LUCAS, J. A. Gustatory cross adaptation between salts. Psychonomic Science, 1966, 4, 301-302.
MEISELMAN, H. L. Adaptation and cross-adaptation of the four gustatory qualities: A study of receptor specificity. Doctoral dissertation, University of Massachusetts, Ann Arbor, Michigan: University Microfilms, 1968a, No. 68-2764.

MEISELMAN, H. L. Magnitude estimations of the course of gustatory adaptation. Perception \& Psychophysics, 1968b, 4, 193-196.

MEISELMAN, H. L., \& DZENDOLET, E. Variability in gustatory quality identification. Perception \& Psychophysics, 1967, 2, 496-498.

MYERS, J. L. Fundamentals of experimental design. Boston: Allyn and Bacon, 1966.

PFAFFMANN, C. The sense of taste. In J. Field, H. W. Magoun and V. E. Hall (Eds.), Handbook of physiology, Section I: Neurophysiology, Vol. I. Washington, D. C.: American Physiological Society, 1959. Pp. 507-533.

PFAFFMANN, C. Taste, its sensory and motivating properties. American Scientist, 1964, 52, 187.206.

\section{NOTES}

1. This report is based on a thesis submitted in partial fulfillment of the requirements for the Ph.D. at the University of Massachusetts. Appreciation is expressed to Ernest Dzendolet for his advice throughout the research. The research was supported in full by a Predoctoral Fellowship from the United States Public Health Service, National Institutes of Mental Health (1-F1-MH-34,451-01). Preparation of the manuscript was completed during a Postdoctoral Fellowship from the same source (1-F2-MH-34,451-01).

2. Present address: Department of Psychology, and Section on Neurobiology and Behavior, Cornell University, Liddell Laboratory, lthaca, New York.

(Accepted for publication August 14, 1968.) 